\title{
Impact of leptin receptor gene variants on risk of non-alcoholic fatty liver disease and its interaction with adiponutrin gene.
}

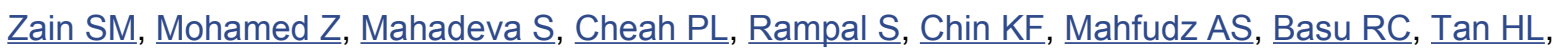
Mohamed R.

\section{Author information}

- The Pharmacogenomics Laboratory, Department of Pharmacology, University of Malaya, Kuala Lumpur, Malaysia. soulz712@gmail.com

\section{Abstract \\ BACKGROUND AND AIM:}

Genetic polymorphism has been implicated as a factor for the occurrence of non-alcoholic fatty liver disease (NAFLD). This study attempted to assess whether polymorphisms in the leptin receptor (LEPR) gene and its combined effect with patatin-like phospholipase domain-containing protein 3 (PNPLA3/adiponutrin) are associated with risk of NAFLD.

\section{METHODS:}

A total of 144 biopsy-proven NAFLD and 198 controls were genotyped using the Sequenom MassARRAY platform.

\section{RESULTS:}

We observed a significant association between the LEPR rs1137100 and rs1137101 with susceptibility to NAFLD (odds ratio [OR] 1.64, 95\% confidence interval [Cl] 1.18-2.28, $\mathrm{P}=0.003$; and OR $1.61,95 \% \mathrm{Cl} 1.11-2.34, \mathrm{P}=0.013$, respectively) and to non-alcoholic steatohepatitis (OR 1.49, $95 \% \mathrm{Cl} 1.05-2.12, \mathrm{P}=0.026$; and $\mathrm{OR} 1.57,95 \% \mathrm{Cl} 1.05-2.35, \mathrm{P}=0.029$, respectively). The LEPR rs 1137100 is also associated with simple steatosis (OR 2.27, 95\% $\mathrm{Cl} 1.27-4.08, \mathrm{P}=0.006$ ). Analysis of gene-gene interaction revealed a strong interaction between the LEPR and PNPLA3 genes (empirical $P=0.001$ ). The joint effect of LEPR and PNPLA3 greatly exacerbated the risk of NAFLD (OR $3.73,95 \% \mathrm{Cl} 1.84-7.55, \mathrm{P}<0.0001$ ). The $\mathrm{G}$ allele of $\mathrm{rs} 1137100$ is associated with lower fibrosis score (OR 0.47, 95\% $\mathrm{Cl} 0.28-0.78, \mathrm{P}=0.001)$.

\section{CONCLUSIONS:}

We report an association between variants of LEPR rs1137100 and rs1137101 with risk of NAFLD. This study suggests that rs 1137100 , specifically the $G$ allele, is associated with a less severe form of liver disease in patients with NAFLD. The interaction between LEPR and PNPLA3 genes showed increased risk of NAFLD compared to either gene alone.

(c) 2012 Journal of Gastroenterology and Hepatology Foundation and Wiley Publishing Asia Pty Ltd.

PMID:

23278404

[PubMed - indexed for MEDLINE] 